\title{
Regional Bank Consolidation and SMEs' Credit Availability: Evidence from China
}

\author{
Xiaohui Hou $\mathbb{D D}^{1}{ }^{1}$ Wei He, ${ }^{1}$ and Kong-Lin $\mathrm{Ke}^{2}$ \\ ${ }^{1}$ School of Economics and Finance, Xi'an Jiaotong University, Xi'an, Shaanxi 710061, China \\ ${ }^{2}$ School of Finance, Zhejiang Gongshang University, Hangzhou, Zhejiang 310018, China \\ Correspondence should be addressed to Xiaohui Hou; hxiaoh2006@163.com
}

Received 5 July 2021; Accepted 15 October 2021; Published 23 October 2021

Academic Editor: Sameh S. Askar

Copyright (C) 2021 Xiaohui Hou et al. This is an open access article distributed under the Creative Commons Attribution License, which permits unrestricted use, distribution, and reproduction in any medium, provided the original work is properly cited.

We conjecture that locally government-led bank consolidation may negatively affect the SMEs' credit availability in China because the breakdown of privately benefit-based relationships among small business borrowers, loan officers, and senior managers could reduce loan officers' incentives to use their soft information. Empirical results show that this is indeed the case.

\section{Introduction}

Bank consolidation is primarily led by markets in developed countries, whereas the governments are often the driving forces of consolidation in emerging economies. In particular, the effect of regional bank consolidation on credit availability to opaque small businesses is still ambiguous under the current research model of small- and mediumsized enterprise (SME) lending [1].

In this paper, we provide rigorous empirical evidence of the impact of a locally government-led consolidation of regional banks on SMEs' credit availability in China. At the end of 2004, "Outline for the Supervision and Development of City Commercial Banks" was promulgated by China's Banking Regulatory Commission. Since 2005, the reform programs of the consolidation of regional banks were issued successively by each province. Regional city commercial banks and urban credit cooperatives, as the foremost financing source for SMEs, were consolidated and restructured in one province after another.

Berger and Udell [2] show that bank lending can be viewed as the outcome of a hierarchy of contracting problems; the bank's small business borrowers contract with the bank's loan officers who in turn contract with the bank's senior management. Because relationship lending depends on the soft information of the loan officer, the consolidating banks may reduce credit supply for SMEs when loan officers temporarily leave their jobs. Nevertheless, a government-led consolidation of regional banks may not have a significantly negative impact on SMEs' credit availability because the loan officer is the repository of much of the soft information, and a government-led bank consolidation is very rarely involved in the active job cuts of loan officers for the purpose of maintaining in-system stability.

However, whether consolidated regional banks can access soft information is one thing and whether loan officers have incentives to fully utilize soft information is another. Even when the soft information mainly endures in banks, the breakdown of privately benefit-based relationships among all three parts, namely, small business borrowers, loan officers, and senior management, may negatively affect loan officers' incentives to use their soft information, thus giving rise to a significant decrease in urban manufacturing SMEs' credit availability. In particular, under the circumstances of stringent interest rate control, strong SMEs' credit constraints, and low degree of law enforcement, the implicit value of this privately benefit-based relationship is expected to be revealed by investigating how its breakdown may offset the positive consolidation effects of the advantages of hardinformation technologies and stronger credit supply impetus from local governments, thereby reducing regional SMEs' credit availability. 


\section{Related Data}

Our SMEs' data are drawn from China's Survey of Manufacturing Firms filed by industrial firms with the National Bureau of Statistics (NBS) from 1998 through 2013. There are no new survey data released by NBS since 2013. Additionally, in the light of hitherto practical interest control, our study can focus on the influence of bank consolidation on credit availability instead of a change of the interest rate. According to the "Classification Standard of Small and Medium-sized Enterprises," formulated by China's Ministry of Industry and Information Technology, a SME is defined as an enterprise whose employees' number is fewer than 1000 and whose operating income is no more than 400 million CNY. The data of the SMEs located in rural areas are eliminated. Our sample totally has 67,611 observations.

To include a set of control variables, we also exploit the information on the regional banking system and socioeconomic backgrounds over many years, primarily from the Almanac of China's Finance and Banking, the Almanac of Finance and Banking at Provincial level, the Statistical Yearbook of Commercial Banks, the CEIC Database, Wind Financial Terminal and Economic Database, and the CSMAR Database. The information on the government-led consolidation of regional banks in various provinces employed to construct our treatment variable is manually collected from publicly available provincial official government documents. The impact of price fluctuations on our variables is eliminated. We winsorize the continuous variables within the interval of $(1 \%, 99 \%)$.

\section{Identification Methodology}

Following the methodology of [3], we adopt a difference-indifferences (DID) strategy with multiway fixed effects, shown in equation (1), and built on a specification in contributions to credit availability. According to [4], the firm-level individual fixed effects should not be controlled to avoid the estimation problem of too high dimension and the excessive absorption of effects of firm-level variables:

$$
Y_{\text {fipt }}=\beta D_{p t}+\theta_{\text {ind }}+\theta_{\text {pro }}+\theta_{t}+\gamma^{\prime} X+\varepsilon_{\text {fipt }} \text {, }
$$

where $Y_{\text {fipt }}$ is the credit availability variable that are defined as the logarithm of the total amount of credit per firm belonging to an industrial sector in a province and year (Credit1) and the ratio of interest payments to total sales (Credit2) [5], respectively, $D_{p t}$ is the treatment variable that is equal to 1 if the policy of regional bank consolidation is implemented within a year in a province, and 0 otherwise, $\varepsilon_{\text {fipt }}$ is an error term, and $\theta_{\text {ind }}, \theta_{\text {pro }}$, and $\theta_{t}$ are industry, province, and time fixed effects, respectively. Following [6], $X$ is a vector of once-lagged control variables that are pretreated covariates including firm characteristics, regional banking market structures, and socioeconomic backgrounds (see the notes to Table 1). In control variables, firm size is one proxy for whether there is hard information about a firm [7]; soft information is controlled by the provincial-level density of bank branches [8].
Finally, the other determinants of the supply and demand sides of the SMEs for credit are also controlled.

Considering that the industry fixed effects in various provinces may affect both the SMEs' credit availability and the treatment variable, we further implement an even more general research design that accounts for the unobserved confounders that vary at the industry $\times$ province $\left(\delta_{\text {indpro }}\right)$ level. A particular version of a triple differenced (DDD) regression model, equation (2), is as follows:

$$
Y_{\text {fipt }}=\beta D_{p t}+\theta_{\text {ind }}+\theta_{\text {pro }}+\theta_{t}+\delta_{\text {indpro }}+\gamma^{\prime} X+\varepsilon_{\text {fipt }} .
$$

Because our treatment, the variable is highly collinear with fixed effects of province $\times$ year, and it cannot be controlled in our DDD specification; however, the industry $\times$ year effects reflect a change in the industrial technology over time, which is more difficult to imagine as a confounder affecting both SMEs' credit availability and regional banks.

Finally, we conduct several robustness regressions to address the potential endogeneity problem. First, we employ the fiscal gap (Pfgap) that is defined as a multiple of the fiscal expenditures to fiscal revenues at the provincial level per year as an instrument variable of $D_{p t}$, Pfgap is expected to impact the incentives of local governments to carry out the consolidation of regional city commercial banks and urban credit cooperatives to strengthen financial resources while not directly affecting the SMEs' credit availability. Second, to relax the SUTVA, we estimate a model for fitting the average treatment effects of the bank consolidation policy on the SMEs' credit availability in the presence of correlated neighborhood interactions at the provincial level [9]. Third, since a significantly negative treatment effect comes from the attenuated implicit value of privately benefit-based relationships, we should observe that the mechanisms of the negative impact of $D_{p t}$ on credit availability weakens in the provinces with higher anticorruption efforts (Hnspc), which is a dummy equal to 1 when the logarithm of number of filed duty crimes of officials in a province is greater than its median or have a better market intermediary and legal environment, namely, higher market environment scores (Smlb) [10].

\section{Results and Discussion}

Table 1 reports the coefficient estimates of $D_{p t}$ for equations (1) and (2). We find that our argument receives empirical support. In the specification of DID equation (1), the implementation of regional bank consolidation reduces SMEs' credit availability by $2.4 \%$ and $2.6 \%$ without and with our whole control variables, respectively, when the explained variable is Credit1; the consolidation reduces credit availability by $0.058 \%$ and $0.086 \%$, respectively, when the explained variable is Credit2. A dynamic DID model, with 2 pretreatment and posttreatment periods, is employed to test for parallel trend. The results show that the parallel trend tests can pass for our equation (1), which alleviates the concern of policy selection bias and justifies our DID settings. 
TABLE 1: The impact of bank consolidation on SMEs' credit availability.

\begin{tabular}{|c|c|c|c|c|c|c|c|c|}
\hline & \multicolumn{4}{|c|}{ Equation (1) } & \multicolumn{4}{|c|}{ Equation (2) } \\
\hline & \multicolumn{2}{|c|}{ Credit1 } & \multicolumn{2}{|c|}{ Credit2 } & \multicolumn{2}{|c|}{ Credit1 } & \multicolumn{2}{|c|}{ Credit2 } \\
\hline & $(1)$ & $(2)$ & $(1)$ & $(2)$ & $(1)$ & $(2)$ & $(1)$ & $(2)$ \\
\hline$D_{p t}$ & $\begin{array}{c}-0.024^{* * *} \\
(0.008)\end{array}$ & $\begin{array}{c}-0.026^{* *} \\
(0.011)\end{array}$ & $\begin{array}{c}-0.058^{* *} \\
(0.025)\end{array}$ & $\begin{array}{c}-0.086^{* *} \\
(0.040)\end{array}$ & $\begin{array}{c}-0.032^{* * *} \\
(0.008)\end{array}$ & $\begin{array}{c}-0.029^{* * *} \\
(0.011)\end{array}$ & $\begin{array}{c}-0.059^{* *} \\
(0.025)\end{array}$ & $\begin{array}{c}-0.079^{* *} \\
(0.040)\end{array}$ \\
\hline
\end{tabular}

Notes: the standard errors, in brackets, are clustered at the firm level. ${ }^{*}$ is $p$ val $<0.1,{ }^{* *}$ is $p$ val $<0.05$, and ${ }^{* * *}$ is $p$ val $<0.01$. In columns $(1)$ and $(2)$, we estimate the models without and with control variables, respectively. Control variables consist of the ratio of accounts receivable to total sales, logarithm of annual sales, logarithm of firm age, ROA, ratio of net working capital to total assets, ratio of tangible assets to total assets, firm leverage, state ownership, and internationalization dummy equal to 1 if firms export products, ratio of equity to assets, provincial banking market concentrations calculated in local deposit share of big four state-owned banks and 13 national joint-stock banks, the number of bank branches in a province per million square kilometers, regional GDP per capita, unemployment rate, logarithm of population, GDP growth rate, ratio of output value of the tertiary industry to GDP, and proportion of output value of state-owned firm in the local industry. $p$ value of $\mathrm{F}$ tests are all less than 0.01 .

Nevertheless, we still further control for the industry $\times$ province effects based on equation (2); these negative impacts are $3.2 \%$ and $2.9 \%$ without and with the control variables, respectively, when the explained variable is Credit1; these negative impacts are $0.059 \%$ and $0.079 \%$, respectively, when the explained variable is Credit2. Moreover, Table 2 reports the estimation results using an instrument variable for our treatment variable and fitting the average treatment effects in the presence of correlated neighborhood interactions at the provincial level. Compared with the estimates in Column (2) for Credit1 and Credit2 under equation (1), a reducing effect of bank consolidation seems to be stronger. These findings suggest that our empirical results are truly robust after addressing the main endogeneity concerns.

Finally, some of the reducing effect could be mechanical. We expect to observe that the negative impact of $D_{p t}$ weakens in the provinces with higher anticorruption efforts or with better market intermediary and legal environments, where the original implicit value of privately benefit-based relationships is lower such that the offsetting effect against bank consolidation advantages would be weaker. It is shown that the moderating effects of Hnspc and Smlb are all positive at the $1 \%$ significant level, which further supports our argument.

Although to maintain in-system stability, a governmentled bank consolidation is very rarely involved in the active job cuts of loan officers, the repository of much of the soft information, and the breakdown of privately benefit-based relationships among all three parts, namely, small business borrowers, loan officers, and senior management, can negatively affect loan officers' incentives to use their soft information, thus giving rise to a significant decrease in urban manufacturing SMEs' credit availability.

The government-led consolidation of regional banks has a significantly negative impact on SMEs' credit availability in the context of an emerging economy such as China even when the soft information still mainly endures in banks. The potential positive consolidation effects of the advantages of hard-information technologies and stronger credit supply impetus from local governments are totally offset by the breakdown of the implicit value derived from the privately benefit-based relationships.
TABLe 2: The impact of bank consolidation on SMEs' credit availability: robustness tests.

\begin{tabular}{|c|c|c|c|c|}
\hline & \multicolumn{2}{|c|}{$\begin{array}{l}\text { IV estimation for } \\
\text { equation (1) }\end{array}$} & \multicolumn{2}{|c|}{$\begin{array}{c}\text { ATE with } \\
\text { neighborhood } \\
\text { interactions }\end{array}$} \\
\hline & Credit1 & Credit2 & Credit1 & Credit2 \\
\hline$D_{p t}$ & $\begin{array}{c}-0.642^{* * *} \\
(0.250)\end{array}$ & $\begin{array}{c}-2.270^{* *} \\
(0.932)\end{array}$ & $\begin{array}{c}-0.064^{*} \\
(0.036)\end{array}$ & $\begin{array}{c}-0.174^{* *} \\
(0.072)\end{array}$ \\
\hline
\end{tabular}

Notes: see notes of Table 1 . Our estimations pass the tests of underidentification and weak identification. For ATE estimation with neighborhood interactions, only the provincial-level control variables are included, since our focus is provincial average SMEs' credit availability. $p$ value of $\mathrm{F}$ tests are all less than 0.01 .

\section{Conclusions}

Our empirical results show that even when soft information mainly endures in banks, hard-information technologies advance, and credit supply impetus from local governments potentially strengthens after consolidation, the breakdown of privately benefit-based relationships among small business borrowers, loan officers, and senior managers may negatively affect loan officers' incentives to use their soft information, giving rise to a significant decrease in SMEs' credit availability. Our primary result has significant implications for the policy practice on the consolidation of regional banks. The regulatory authorities should take account of optimizing the incentive mechanism for the staff of the regional banks suffering from the influences of a government-led consolidation.

\section{Data Availability}

Our SMEs' data are drawn from China's Survey of Manufacturing Firms filed by industrial firms with the National Bureau of Statistics (NBS).

\section{Conflicts of Interest}

The authors declare that there are no conflicts of interest regarding the publication of this paper. 


\section{Acknowledgments}

The authors gratefully acknowledge the financial support from a program of "The PATH and Strategy of Micro Finance Development Integrated with the Yangtze River Delta."

\section{References}

[1] A. N. Berger, "Small business lending by banks: lending technologies and the effects of banking industry consolidation and technological change," in The Oxford Handbook of Banking, A. N. Berger, P. Molyneux, and J. O. S. Wilson, Eds., pp. 292-311, Oxford University Press, Oxford, UK, 2015.

[2] A. N. Berger and G. F. Udell, "Small business credit availability and relationship lending: the importance of bank organization structure," The Economic Journal, vol. 112, no. 477, p. 32, 2002.

[3] S. Correia, "Reghdfe: estimating linear models with multi-way fixed effects," in Proceedings of the 2016 Stata Conference 24, Stata Users Group, London, UK, September 2016.

[4] A. N. Berger, G. Cerqueiro, and M. F. Penas, "Market size structure and small business lending: are crisis times different from normal times?" Review of Finance, vol. 19, no. 5, pp. 1965-1995, 2015.

[5] R. Cull, L. C. Xu, and T. Zhu, "Formal finance and trade credit during China's transition," Journal of Financial Intermediation, vol. 18, no. 2, pp. 173-192, 2009.

[6] M. Psillaki and K. Eleftheriou, "Trade credit, bank credit, and flight to quality: evidence from French SMEs," Journal of Small Business Management, vol. 53, no. 4, pp. 1219-1240, 2015.

[7] A. N. Berger, N. H. Miller, M. A. Petersen, R. G. Rajan, and J. C. Stein, "Does function follow organizational form? Evidence from the lending practices of large and small banks," Journal of Financial Economics, vol. 76, no. 2, pp. 237-269, 2005.

[8] P. Alessandrini, A. F. Presbitero, and A. Zazzaro, "Banks, distances and firms' financing constraints," Review of Finance, vol. 13, no. 2, pp. 261-307, 2009.

[9] G. Cerulli, "Identification and estimation of treatment effects in the presence of (correlated) neighborhood interactions: model and Stata implementation via ntreatreg," STATA Journal: Promoting communications on statistics and Stata, vol. 17, no. 4, pp. 803-833, 2017.

[10] G. Fan, X. L. Wang, and H. P. Zhu, NERI INDEX of Marketization of China's Provinces 2011 Report, Economic Science Press, Beijing, China, 2011. 